\title{
Structural Properties of Highly Doped Borazino Polyphenylenes Obtained through Condensation Reaction
}

\author{
Jacopo Dosso, ${ }^{\dagger, \S}$ Davide Marinelli, ${ }^{\dagger, \S}$ Nicola Demitri, ${ }^{\ddagger \odot}$ and Davide Bonifazi ${ }^{*}, \dagger$ \\ ${ }^{\dagger}$ School of Chemistry, Cardiff University, Park Place, Cardiff CF10 3AT, U.K. \\ ${ }^{\ddagger}$ Elettra-Sincrotrone Trieste, S. S. 14 km 163.5 in Area Science Park, Basovizza 34149, Trieste, Italy
}

\section{Supporting Information}

ABSTRACT: Here we describe the synthesis and spectroscopic and structural characterization of various borazine-doped polyphenylenes displaying high doping dosages (16-18\%). Capitalizing on the condensation reaction approach, the desired products were formed using a mixture of $p$-phenylendiamine and aniline with $\mathrm{BCl}_{3}$, followed by the addition of an aryl lithium derivative. The use of mesityl lithium (MesLi) yields strained multiborazine derivatives, which proved to be unstable in the presence of moisture. However, when xylyl lithium (XylLi) was used, chemically stable multiborazines were obtained, with oligomers showing molecular weight up to $10^{4}$, corresponding to $16-18$ monomer units. While the dimer, trimer, and tetramer could be isolated as pure products and their structure characterized by mass and NMR analysis, higher oligomers could only be isolated as mixtures of $B$-hydroxy-substituted derivatives and characterized by gel permeation chromatography. The structures of the dimer and trimer derivatives were confirmed by X-ray analysis, which nicely showed the presence of the two and three borazine rings spaced by one and two 1,4-aryl bridges, respectively. Notably, the trimer forms a porous crystalline clathrate. The peripheral xylyl and phenyl moieties of each

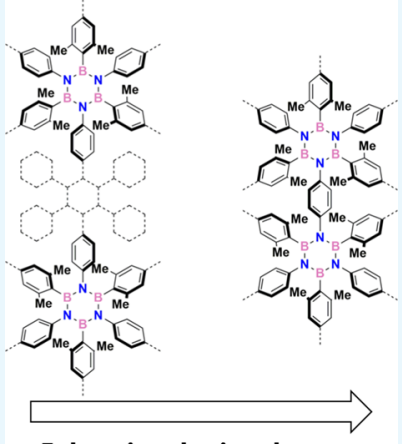

Enhancing doping dosage molecule intramolecularly embrace each other through $\mathrm{C}-\mathrm{H}$ and $\pi-\pi$ stacking interactions. Steady-state UV-vis absorption characterization suggested that the molecules are UV absorbers, with the extinction coefficient linearly scaling with the degree of oligomerization. On the other hand, low-emission quantum yields were obtained for all derivatives $(<7 \%)$, suggesting that high BN-doping dosages dramatically affect the emission properties of the doped polyphenylenes.

\section{INTRODUCTION}

In the last decade, the development of doping methods ${ }^{1-3}$ to replace $\mathrm{C}=\mathrm{C}$ bonds with $\mathrm{B}=\mathrm{N}$ has proved to be one of the most promising synthetic approaches to tailor material properties both at the molecular and the nanoscale levels. ${ }^{4-11}$ The interest is related to the peculiar characteristics of polar $\mathrm{B}=\mathrm{N}$ bonds that, ${ }^{10}$ being isoelectronic and isostructural to $\mathrm{C}=\mathrm{C}$ bonds, allow the tuning of the optoelectronic properties $^{12-14}$ of polycyclic aromatic hydrocarbons and parent molecular graphenes without significant peripheral modifications of the molecular scaffold. ${ }^{15-23}$ In this respect, a lot of efforts have been dedicated to the development of $\mathrm{BN}$-doped polymeric $^{8,24-28}$ and dendrimeric ${ }^{29}$ materials for applications in gas storage and separation, ${ }^{30}$ optoelectronic devices, $^{19,21,22,27,31}$ self-assembly on surfaces, ${ }^{32-34}$ and in the bottom-up synthesis of $\mathrm{BN}$-doped nanographenes. ${ }^{35,36}$ Although suffering from low stability toward hydrolysis, ${ }^{37}$ ElKaderi's porous polyborazino materials, prepared by condensation reaction and used to store $\mathrm{H}_{2}$, are certainly the seminal examples in the field (Figure 1). ${ }^{38,39}$

Inspired by Nagasawa's observations, who reported a moisture-stable $B$-trimesityl- $N$-triphenylborazine in 1965 , and later by the group of Yamaguchi, ${ }^{40}$ our group dedicated a lot of effort on the development of BN-doped polyphenylenes that are chemically and thermally stable. ${ }^{29}$ In particular, we recently described the divergent synthesis of borazino-doped poly- phenylenes, taking advantage of the decarbonylative DielsAlder cycloaddition reaction between ethynyl and tetraphenylcyclopentadienone-borazine based precursors. Owing to the possibility of functionalizing the borazine core with different groups on the aryl substituents at the $\mathrm{N}$ and $\mathrm{B}$ atoms, we have prepared borazino-doped polyphenylenes featuring different doping dosages $(\rho)$ and orientations $(o)$. The $\rho$ value is defined as the percentage of the aryl units that have been substituted with the borazine analogues, whereas the orientational parameter $o$ defines the relative orientation between the doping borazine rings. ${ }^{29}$ Detailed photophysical investigations showed that, increasing the $\rho$ value to $6 \%$, the strong fluorescent signal is progressively reduced. On the contrary, a negligible effect of the orientational $o$ doping was observed. This observation suggested that high values of $\rho$ accelerated the nonradiative deactivation of the singlet excited state through a possible combination of intersystem crossing, increased charge separation character of the excited state and vibrational relaxation. ${ }^{29}$ To further expand and study the doping portfolio of polyphenylenes, we envisaged to prepare oligomeric $\mathrm{BN}$-doped polyphenylenes featuring higher doping dosages. Conceptually, high $\rho$ values can be achieved either by

Received: March 26, 2019

Accepted: May 6, 2019

Published: May 28, 2019 
Synthesis of borazino-doped BNC arrays through condensation reaction

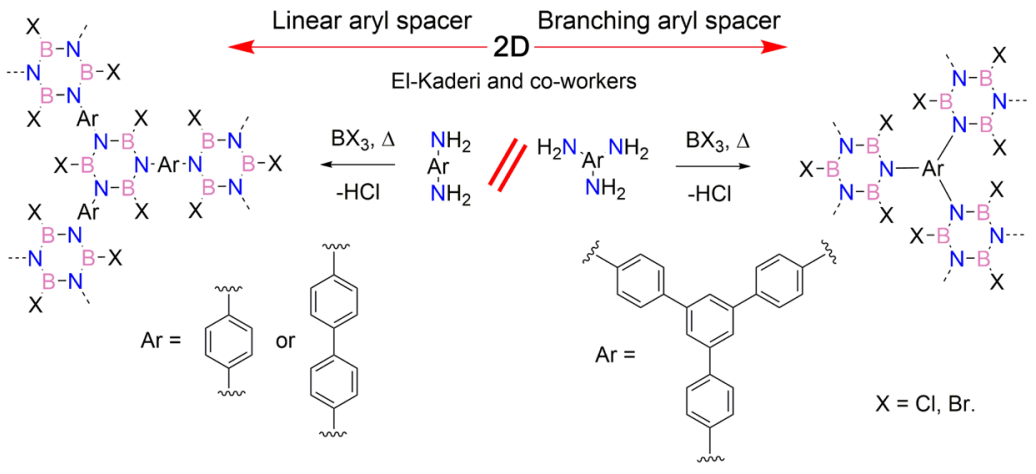

Discrete oligomeric borazino-doped BNC derivatives

$$
\text { Discrete oligomeric borazino-doped BNC derivatives }
$$

Figure 1. Synthetic strategy toward borazino-doped polymers and oligomers.

(i) replacing as many phenyl rings as possible with borazine rings or (ii) reducing the number of peripheral and core phenyl rings. Building on the latter approach, in this work we report on the synthesis of oligomeric borazines in which the hexaphenyl aryl bridge is replaced by 1,4-aryl linkers. Capitalizing on the condensation reaction between aniline and $\mathrm{BCl}_{3}$ followed by the addition of an organolithium aryl derivative, ${ }^{31,40}$ we have isolated $\mathrm{BN}$-doped polyphenylenes with high $\rho$ values $(>16 \%)$. X-ray characterization confirmed the structures of the dimeric and trimeric borazines, whereas photophysical investigations confirmed the UV-absorption properties of the materials, as well as their doping-dependent emission properties.

\section{RESULTS AND DISCUSSION}

Building on El-Kaderi's approach, ${ }^{38,39}$ we attempted the preparation of borazine-doped polyphenylenes using $\mathrm{BCl}_{3}$ in the presence of a given mixture of aniline and $p$-phenylendiamine in refluxing toluene (Scheme 1a). A first attempt was carried out using a 4:1 mixture of aniline and $p$-phenylendiamine with $\mathrm{BCl}_{3}$, followed by the addition of MesLi. Purification of the reaction mixture with $\mathrm{SiO}_{2}$ gel column chromatography led to the isolation of $\mathbf{1}^{\text {Mes }}$ and $2^{\text {Mes }}$ in 10 and $2 \%$ yield, respectively. When using a $2: 1$ ratio of aniline and $p$ phenylendiamine, high quantities of oligoborazinic fractions were obtained after addition of MesLi. Similarly, molecule $\mathbf{1}^{\text {Mes }}$ was isolated in $6 \%$ yield along with a fraction containing a mixture of oligomers. Separation of the oligomeric mixture via recycling-gel permeation chromatography (Rec-GPC, Scheme $1 b)$ led to the isolation of dimer $2^{\text {Mes }}$ ( $5 \%$ yield) and a fraction containing trimer $3^{\text {Mes }}$ ( $3 \%$ yield). The molecular structures of the oligomers were identified by NMR spectroscopy and mass spectrometry, the latter allowing the detection of the peak corresponding to the molecular ion $\left(\mathrm{M}^{+}\right)$.

However, degradation of both $2^{\text {Mes }}$ and in particular $3^{\text {Mes }}$ was noticed upon exposure to ambient moisture condition, which made the isolation of pure $3^{\text {Mes }}$ an impossible task using classical chromatographic techniques. Suitable crystals for Xray analysis were obtained for molecule $2^{\text {Mes }}$ (Figure 2) by slow evaporation of a $\mathrm{CHCl}_{3}$ solution. As expected, the crystal structure shows the presence of two borazine rings, linked at the nitrogen atoms through a 1,4-aryl spacer. The molecular structure reveals a substantial deviation from the orthogonal arrangement of the aryl substituents and the borazine ring with an interplanar angle between 55.5 and $77.3^{\circ}$. Interestingly, the intra-annular distance values between $\mathrm{B}$ and $\mathrm{N}$ atoms within the borazine rings are between $1.441(1)$ and $1.448(1) \AA$, whereas the average internal $\mathrm{NBN}$ and $\mathrm{BNB}$ angles are $117.09(7)^{\circ}$ and $122.31(7)^{\circ}$, respectively. The central BN core displays a significant structural deformation, with a r.m.s. deviation of $0.14 \AA$ of the core $\mathrm{BN}$ atoms from the average plane.

When looking at the crystal structure of $2^{\mathrm{Mes}}$, one can clearly notice that the 4-methyl group of Mes substituents at the bay position undergoes steric clashes, forcing the two neighboring $\mathrm{BN}$ cores to accommodate on two parallel planes (interplanar distance of $0.14 \AA$ ), straining the dimeric derivative and 
Scheme 1. (a) Condensation Route To Prepare Multiborazino Polyphenylenes. The Addition of $\mathrm{BCl}_{3}$ was $\mathrm{Performed}$ at $80{ }^{\circ} \mathrm{C}$ to Increase the Solubility of $p$-Phenylendiamine in Toluene. (b) Rec-GPC Trace of the Crude Oligomeric $\mathrm{Mixture}$ after $\mathrm{SiO}_{2}$ Gel Column Chromatography, Showing the Waste (Black), Recycle (Blue), and Collection (Red) Sequences. Inset: Zoom of the Chromatogram of the Fourth Cycle

a)

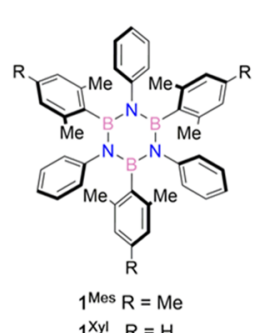
$1^{X y l} \quad R=H$
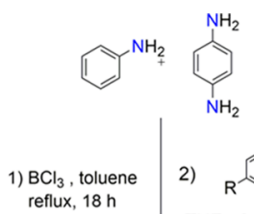

2)

THF, $-84^{\circ} \mathrm{C}$ to r.t., 18
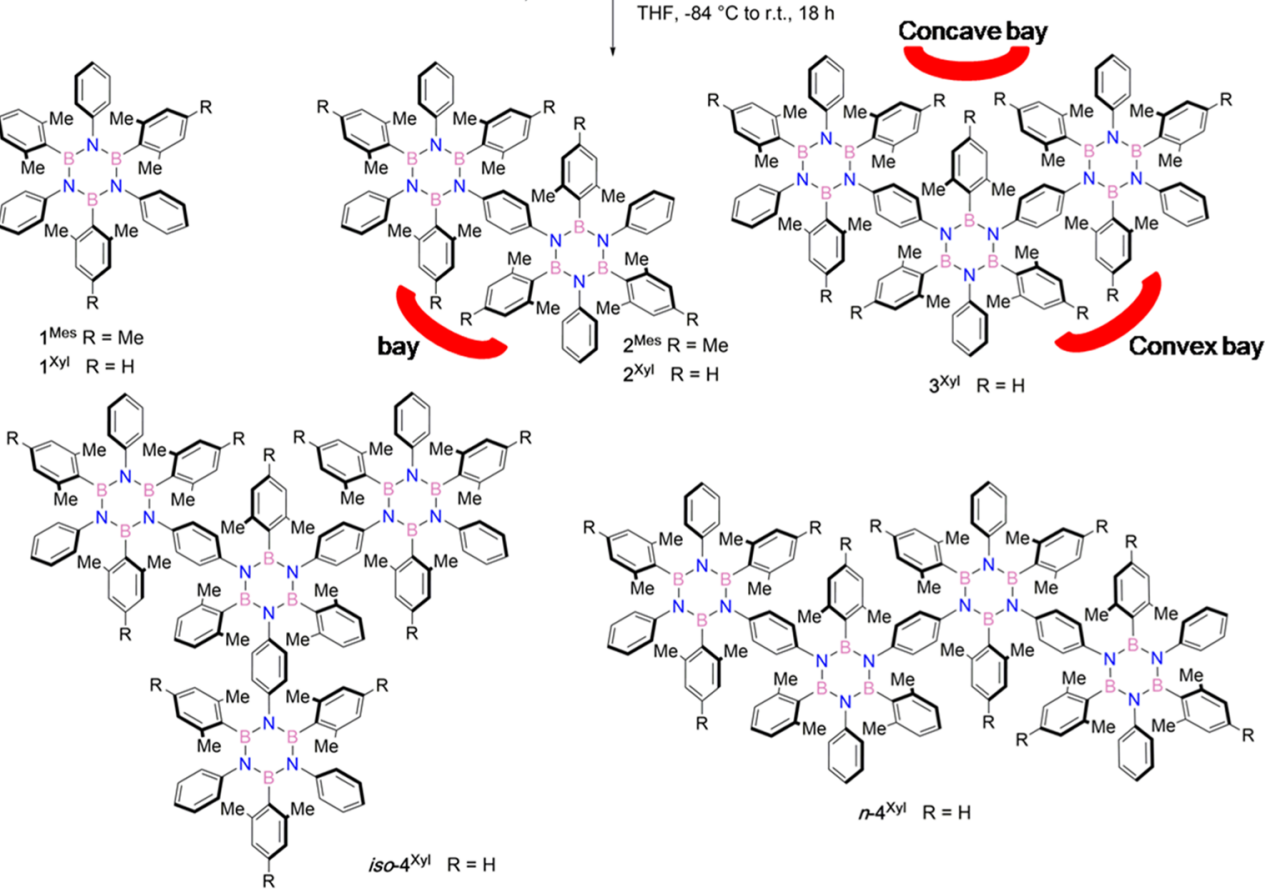

b)

+ Oligomers

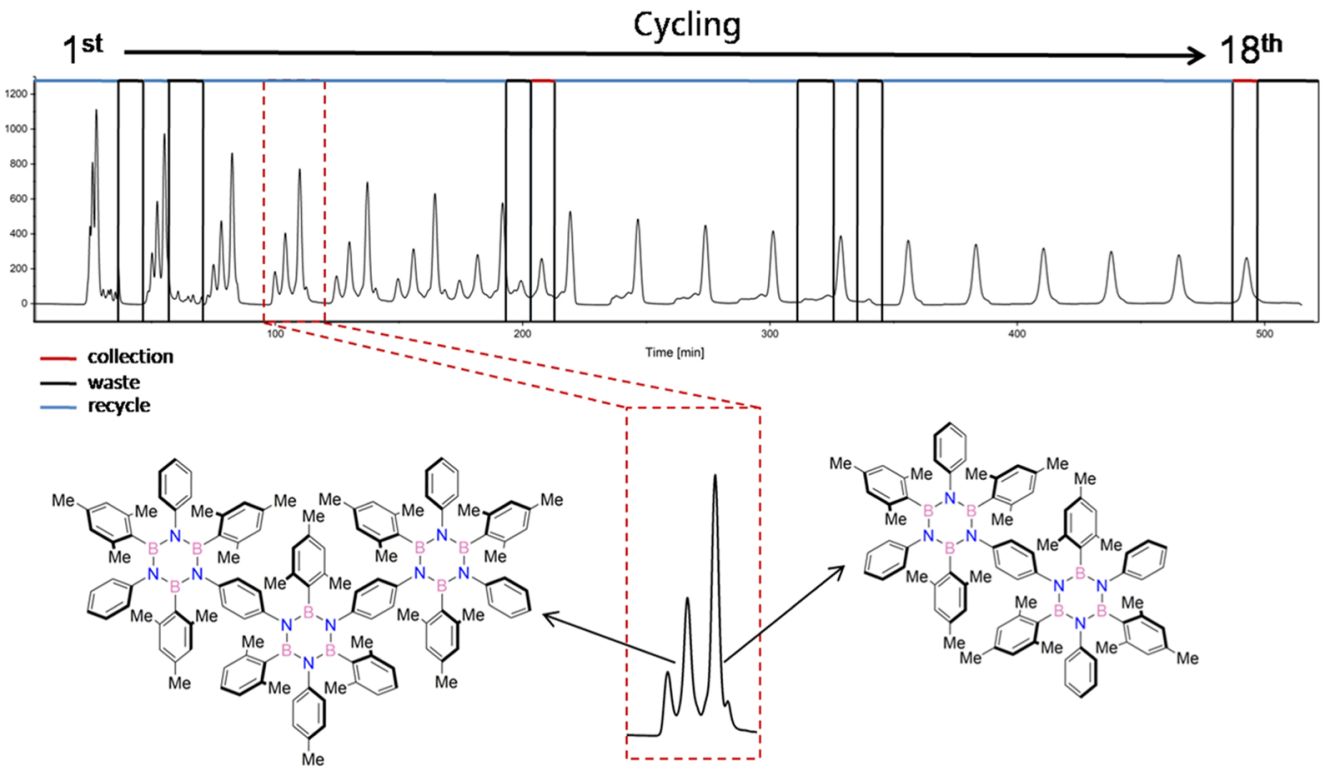

distorting the borazine ring. This results in a reduced steric protection of the boron atoms, which possibly leads to an increased susceptibility of the borazine cores toward hydrolysis. All together, these observations suggest that, if one wants to improve the stability of such oligomeric borazines toward hydrolysis, B-aryl moieties bearing no substituents at the para position should be used. Therefore, we conjectured that addition of xylyl lithium (XylLi) would afford uncongested oligoborazines with a reduced strain content. Building on this idea, we reacted a 2:1 mixture of aniline and $p$-phenylendiamine with $\mathrm{BCl}_{3}$ and quenched it with XylLi. Capitalizing on a combination of multiple chromatographic separations (see the 

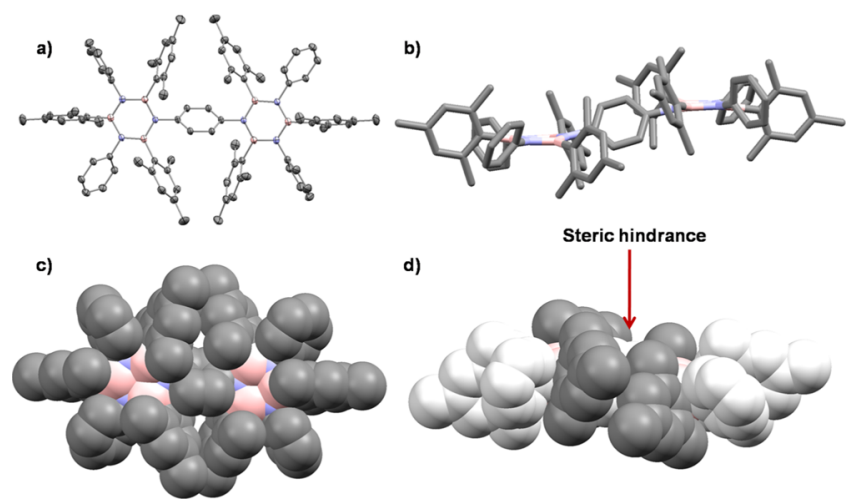

Figure 2. Front (a) and side (b) views of the X-ray structure of $\mathbf{2}^{\text {Mes }}$, with the former depicted as ellipsoids of ASU contents (50\% probability). Front (c) and side (d) views of the vdW representation, clearly depicting the steric clash between the Mes groups close to the bridging 1,4-aryl moiety. Space group: $P b c a$. B: pink, N: blue, C: gray. $\mathrm{H}$ atoms are omitted for clarity reasons.

Supporting Information), we could isolate $1^{\mathrm{Xyl}}$ (16\% yield), $2^{\mathrm{Xyl}}$ ( $7 \%$ yield), $3^{\mathrm{Xyl}}$ ( $1 \%$ yield), $2^{\mathrm{XylOH}}$ ( $2 \%$ yield $), 4^{\mathrm{Xyl}}(0.1 \%$ yield, probably as a mixture of iso and normal isomers, Scheme 1) along with an inseparable mixture of oligomeric products. The structural identity of the monodispersed fractions was first demonstrated by high-resolution mass spectrometry (HRMS), which confirmed the molecular mass for all oligomers $\left(1^{\mathrm{Xyl}}\right.$, $\left[\mathrm{C}_{42} \mathrm{H}_{43} \mathrm{~B}_{3} \mathrm{~N}_{3}\right]^{+}$calcd, 622.3736; found, 622.3766; $2^{\mathrm{Xyl}}$, $\left[\mathrm{C}_{78} \mathrm{H}_{78} \mathrm{~B}_{6} \mathrm{~N}_{6}\right]^{+}$calcd, 1164.6846 ; found, $1164.6812 ; 3^{\mathrm{Xyl}}$, $\left[\mathrm{C}_{114} \mathrm{H}_{114} \mathrm{~B}_{9} \mathrm{~N}_{9}\right]^{+}$calcd, 1708.0035; found, $1707.9987 ; 2^{\mathrm{xylOH}}$, $\left[\mathrm{C}_{70} \mathrm{H}_{70} \mathrm{~B}_{6} \mathrm{~N}_{6} \mathrm{O}\right]^{+}$calcd, 1076.6169; found, 1076.6207; and $4^{\mathrm{Xyl}},\left[\mathrm{C}_{150} \mathrm{H}_{150} \mathrm{~B}_{12} \mathrm{~N}_{12}\right]^{+}$calcd, 2251.3223; found, 2251.3375). As the mixture of higher oligomers could not be separated, the product was analyzed using size exclusion chromatography calibrated on a poly(methylmethacrylate) standard (Figures S31 and S32). GPC analysis suggested that the fraction is mainly composed by oligomers displaying MW up to $10^{4} \mathrm{Da}$, scoring an average molecular weight of $1900 \mathrm{Da}$ and a dispersity of 1.97 . The ${ }^{11} \mathrm{~B}$ NMR spectrum displayed a peak centered at $37.5 \mathrm{ppm}$ (diagnostic for borazine core) together with a low-intensity resonance at $25.2 \mathrm{ppm}$, typical of a boron specie linked to an oxygen atom. Considering that the IR spectrum of these oligomers closely resembles that of $2^{\mathrm{XylOH}}$ (see experimental part) with an intense $\mathrm{OH}$-stretching absorption band centered at $3612 \mathrm{~cm}^{-1}$, it is suggested that higher oligomers are mainly composed of hydroxylated species. Suitable crystals for X-ray diffraction were obtained for $\mathbf{1}^{\mathrm{Xyl}}$ (slow evaporation of $\mathrm{CHCl}_{3}$, Figure 3), $\mathbf{2}^{\mathrm{Xyl}}, 3^{\mathrm{Xyl}}$ (diffusion of pentane in a $\mathrm{CHCl}_{3}$ solution, Figures 4 and 5 ), and $2^{\mathrm{XylOH}}$ (slow evaporation of a $1: 1 \mathrm{CH}_{2} \mathrm{Cl}_{2} /$ petroleum ether mixture, Figures 6 and 7). Whereas the X-ray structure of $\mathbf{1}^{\mathrm{Xyl}}$ closely resembles that obtained from the tri- $B$-mesityl derivatives previously reported by us (Figure 3 ), ${ }^{31}$ the structure of bisborazine $2^{\mathrm{Xyl}}$ is less strained (Figure $4 \mathrm{~d}$ ) than that of its congener, $2^{\text {Mes }}$. Contrary to $2^{\text {Mes }}$, the absence of the 4-methyl groups lessens the steric hindrance between the B-aryl substituents, allowing the two borazine cores in $2^{\mathrm{Xyl}}$ to adopt a tilted conformation with an interplanar angle of $32^{\circ}$ (Figure $4 \mathrm{~b})$. As a result, the boron atoms in the borazine core remain sterically shielded by the methyl groups, thus making derivative $2^{\mathrm{Xyl}}$ chemically stable toward hydrolysis, just as monomeric derivative $\mathbf{1}^{\mathrm{Xyl}}$.

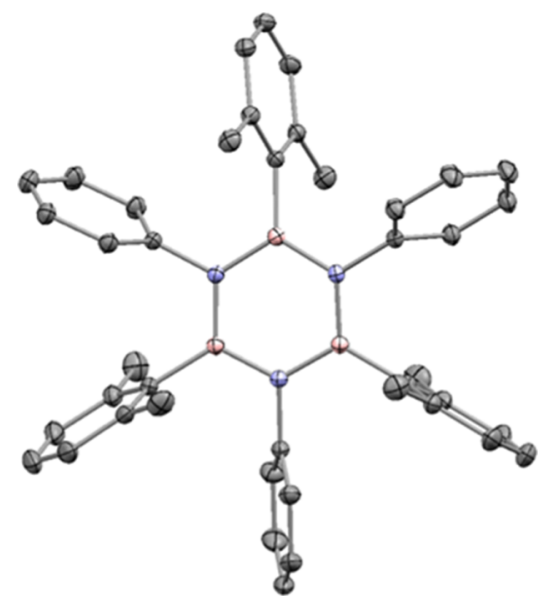

Figure 3. Front view of the $\mathrm{X}$-ray structure of $\mathbf{1}^{\mathrm{Xyl}}$ depicted as ellipsoids of ASU contents ( $50 \%$ probability), crystals obtained by slow evaporation of $\mathrm{CHCl}_{3}$. Space group: Cc. B: pink, N: blue, C: gray. $\mathrm{H}$ atoms are omitted for clarity reasons.

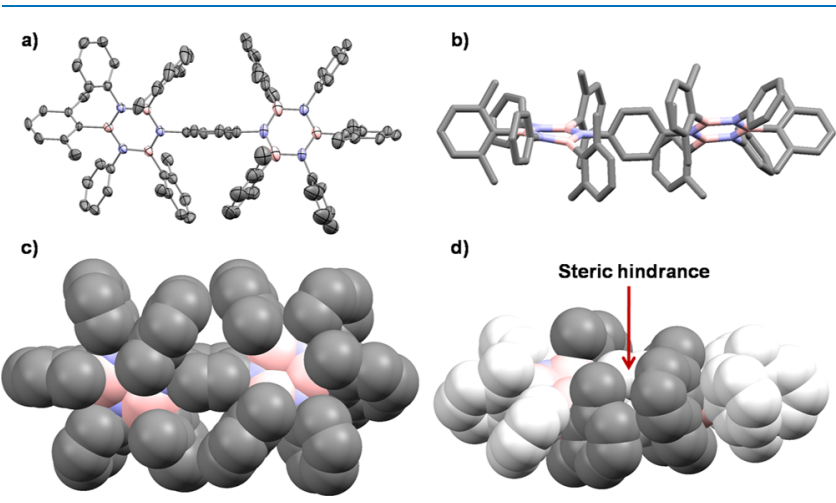

Figure 4. Front (a) and side (b) views of the X-ray structure of $\mathbf{2}^{\mathrm{Xyl}}$, with the former depicted as ellipsoids of ASU contents (50\% probability). Front (c) and side (d) views of the vdW representation, depicting the steric clash between the xylyl groups at the bay position. Space group: $P \overline{1}$. B: pink, $\mathrm{N}$ : blue, $\mathrm{C}$ : gray. $\mathrm{H}$ atoms are omitted for clarity reasons.

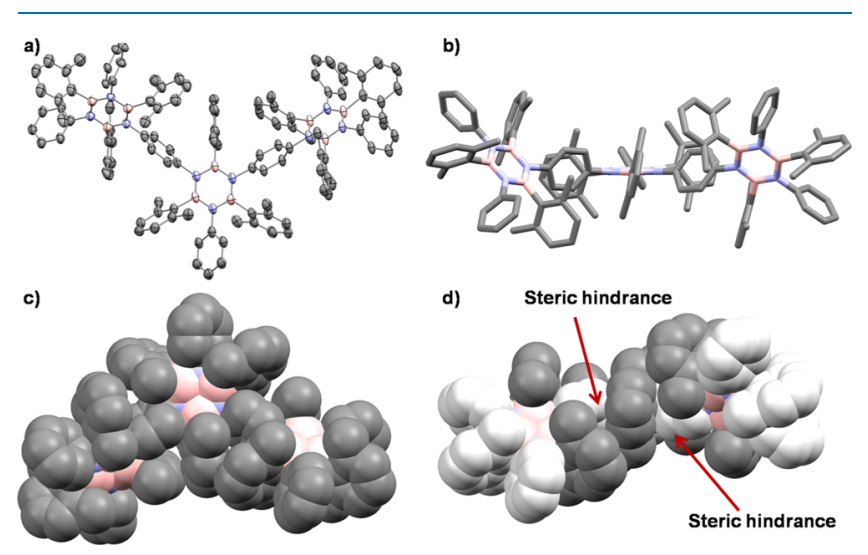

Figure 5. Front (a) and side (b) views of the X-ray structure of $3^{\mathrm{Xyl}}$, with the former depicted as ellipsoids of ASU contents (15\% probability). Front (c) and side (d) views of the vdW representation, depicting the helices-type conformation adopted by the trimer as a consequence of the steric clash between the xylyl groups at the concave bay position. Space group: $P \overline{3}$. B: pink, N: blue, C: gray. $\mathrm{H}$ atoms are omitted for clarity reasons. 


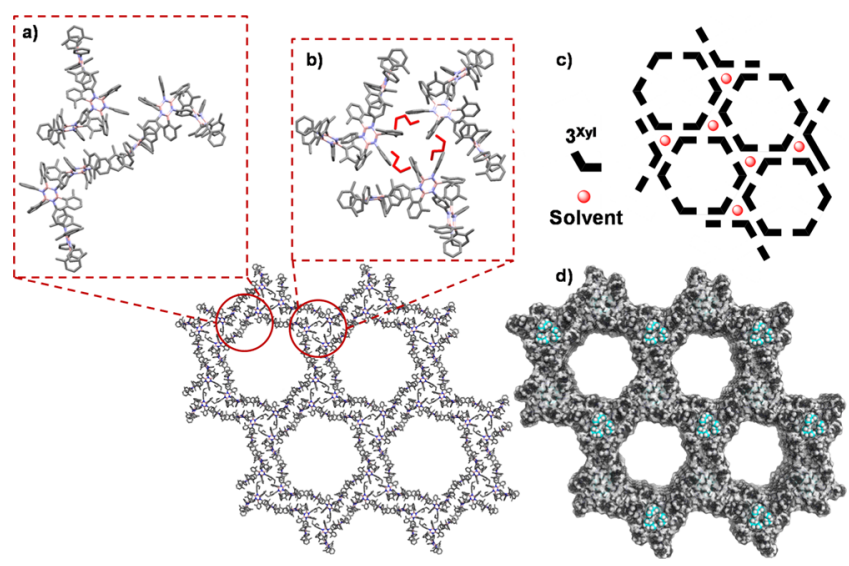

Figure 6. (a,b) Packing arrangement of the porous crystals obtained from $3^{\mathrm{Xyl}}$. Space group: $P \overline{3}$. B: pink, $\mathrm{N}$ : blue, C: gray. $\mathrm{H}$ atoms are omitted for clarity reasons. In red, the pentane molecules. (c) Schematic representation of molecules' arrangement in crystals. (d) $\mathrm{vdW}$ representation of the crystal packing with pores highlighted.
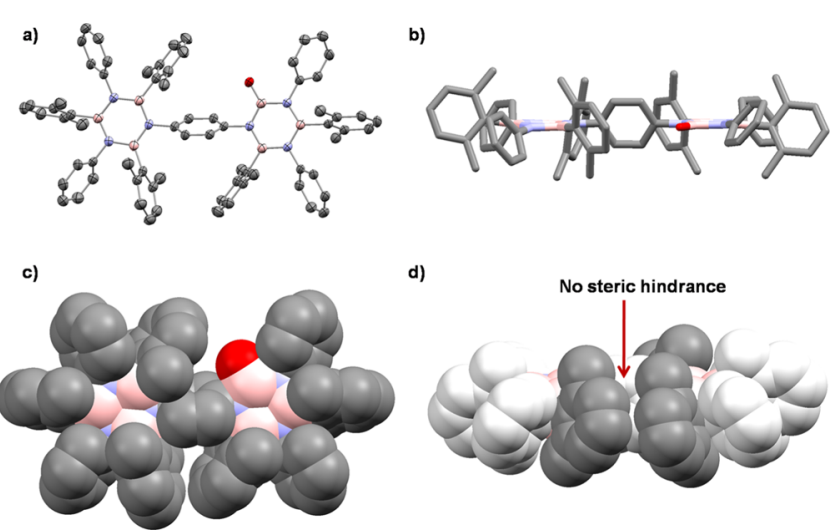

Figure 7. Front (a) and side (b) views of the X-ray structure of $\mathbf{2}^{\mathrm{XylOH}}$ in polymorph $\beta$ with the former depicted as ellipsoids of ASU contents (50\% probability). Front (c) and side (d) views of the vdW representation. Space group: $P 2_{1} / c$. B: pink, $\mathrm{N}$ : blue, C: gray. $\mathrm{H}$ atoms are omitted for clarity reasons.

The same conformational pattern observed for dimer $2^{\mathrm{Xyl}}$ was also noticed in the X-ray structure of $3^{\mathrm{Xyl}}$ (Figure 5). In this case, three borazine units are linked through two 1,4-aryl spacers. If one considers the central borazine as the reference core, the two peripheral borazine rings adopt opposite tilted arrangements because of the steric hindrance between the xylyl substituents at the concave bay position, with interplanar angles of -53.0 and $53.5^{\circ}$, respectively. At the molecular level, the conformation develops into a helicene-type structure, with both enantiomers equally present in the crystal structure (Figure $5 b-d$ ). When looking at the crystal packing, it is apparent that molecule $3^{\mathrm{Xyl}}$ forms a hierarchized hexagonal porous network at the solid state (Figure 6) with each pore surrounded by six molecules and displaying a diameter of $32 \AA$ (Figure 6c). In the hierarchical structure, the molecules between different pores (Figure 6a,b) are held together by $\mathrm{CH}-\pi$ interactions through the interdigitation of peripheral aryl and phenyl groups (Figure 6a). Interestingly, three solvent molecules of pentane are also entrapped in the noncovalent hexagonal framework through $\mathrm{CH}-\pi$ interactions at each vertex.
As far as $2^{\mathrm{XylOH}}$ is concerned, we found out that the molecule can crystallize in two different polymorphs $\alpha$ [unit cell: $a=18.861(4) \AA ̊$; $b=22.390(4) \AA ; ;=14.820(3) \AA]$ and $\beta$ $[a=11.350(2) \AA ; b=16.679(3) \AA ; c=32.207(6) \AA]$, forming rod- and plate-shape crystals, respectively. In both polymorphs, the crystal structure of $2^{\mathrm{XylOH}}$ appears to be strain-free. Whereas in polymorph $\beta$ the two borazine cores adopt an almost co-planar conformation (interplanar angle of $1.5^{\circ}$, Figure $8 \mathrm{~b}$ ), in the $\alpha$ crystals the $\mathrm{BN}$ rings form an interplanar
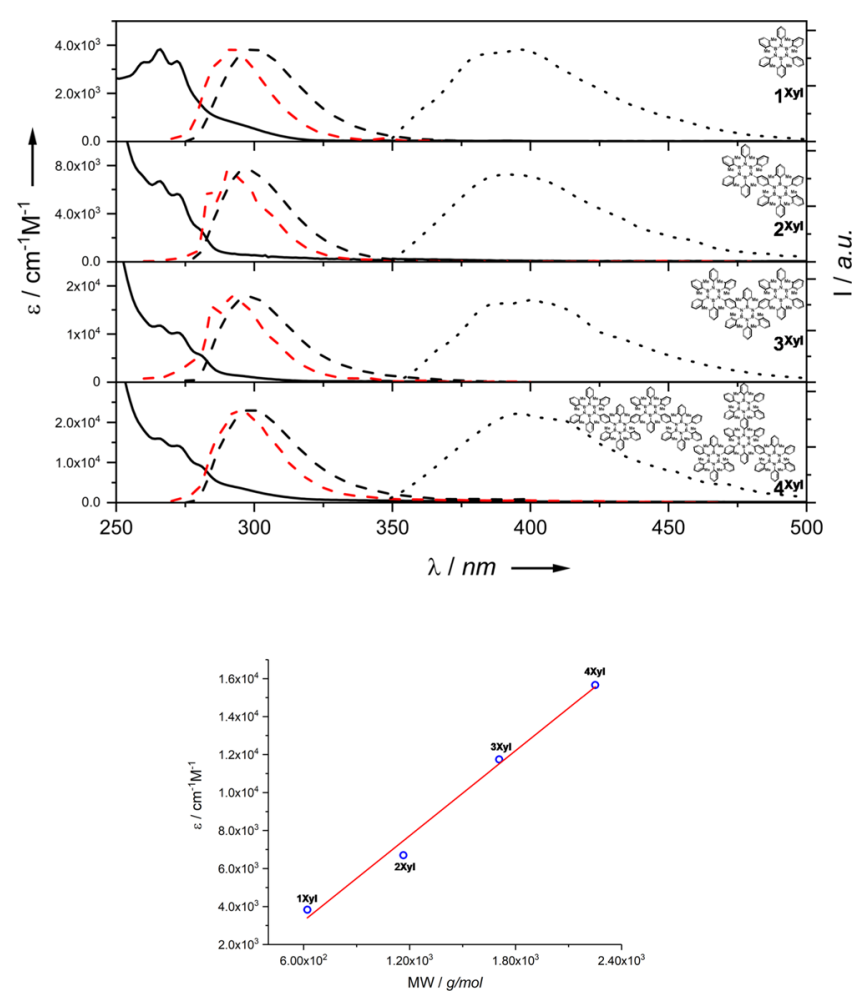

Figure 8. Above: Absorption (solid) and fluorescence (black dashed) in an aerated $\mathrm{CH}_{2} \mathrm{Cl}_{2}$ solution at rt. Fluorescence (red dashed) and phosphorescence (dotted) at $77 \mathrm{~K}$ in a $1: 1 \mathrm{CH}_{2} \mathrm{Cl}_{2} / \mathrm{CHCl}_{3}$ glassy matrix of $1^{\mathrm{Xyl}}\left(\lambda_{\text {exc }}=265 \mathrm{~nm}\right), 2^{\mathrm{Xyl}}\left(\lambda_{\text {exc }}=265 \mathrm{~nm}\right), 3^{\mathrm{Xyl}}\left(\lambda_{\text {exc }}=267\right.$ $\mathrm{nm})$, and $4^{\mathrm{Xyl}}\left(\lambda_{\mathrm{exc}}=267 \mathrm{~nm}\right)$. Below: Correlation between MW and molar extinction coefficient at excitation wavelengths.

angle of $39^{\circ}$ (Figures S4, S5 and S8). If one considers molecule $2^{\mathrm{Xyl}}$ being stable under ambient conditions, it is unlikely that $2^{\mathrm{XylOH}}$ could arise from direct hydrolysis of its arylated derivative. As we could isolate only derivatives bearing the $\mathrm{B}-$ $\mathrm{OH}$ group at the bay position, one can hypothesize that the hydrolysis reaction could occur at the $\mathrm{B}-\mathrm{Cl}$ groups that, being sterically hindered, did not react with XylLi.

In order to study the effect of high doping dosages on the optoelectronic properties of borazine-polyphenylenes, the steady-state UV-vis absorption and emission properties of $1^{\mathrm{Xyl}}, \mathbf{2}^{\mathrm{Xyl}}, 3^{\mathrm{Xyl}}$, and $4^{\mathrm{Xyl}}$ were studied (Figure 8, Table 1). As reported in the absorption spectra displayed in Figure 8a, all borazine-doped polyphenylenes absorb in the UV spectral region, with absorption maxima ranging from 260 to $280 \mathrm{~nm}$. Although the extinction coefficients linearly scale with the molecular size of the oligomers when passing from $1^{\mathrm{Xyl}}$ to $4^{\mathrm{Xyl}}$ (Figure 8b), no significant bathochromic shifts are observed. These observations suggest that the absorption properties of these oligomers are additive, and that no significant $\pi$ conjugation occurs upon extension of the oligomers. 
Table 1. Photophysical Properties of Oligoborazino Derivatives in $\mathrm{CH}_{2} \mathrm{Cl}_{2}$

\begin{tabular}{|c|c|c|c|c|c|c|c|}
\hline \multirow[b]{2}{*}{ molecule } & absorption & \multicolumn{6}{|c|}{ emission } \\
\hline & $\lambda[\mathrm{nm}]\left(\varepsilon,\left[\mathrm{M}^{-1} \mathrm{~cm}^{-1}\right]\right)^{a}$ & $\lambda_{\max , \mathrm{fl}}{ }^{a}[\mathrm{~nm}]$ & $E_{\text {opt }}^{b}[\mathrm{eV}]$ & $\tau_{\mathrm{fl}}[\mathrm{ns}]$ & $\Phi_{\mathrm{fl}}{ }^{c}$ & $\lambda_{\text {max }, \mathrm{ph}}{ }^{d}[\mathrm{~nm}]$ & $\tau_{\mathrm{ph}}^{d}[\mathrm{~s}]$ \\
\hline \multirow[t]{3}{*}{$1^{\mathrm{Xyl}}$} & $260(3300)$ & 300 & 4.31 & 1.24 & 0.02 & 383 & $1.11^{e}$ \\
\hline & $266(3831)$ & & & & & & $1.42(76 \%)$ \\
\hline & $272(3342)$ & & & & & & $0.37(24 \%)$ \\
\hline \multirow[t]{3}{*}{$2^{\mathrm{Xyl}}$} & $266(6702)$ & 297 & 4.18 & 1.66 & 0.02 & 389 & $1.49^{e}$ \\
\hline & $272(5630)$ & & & & & & $1.70(88 \%)$ \\
\hline & $280(2755)$ & & & & & & $0.27(12 \%)$ \\
\hline \multirow[t]{3}{*}{$3^{\mathrm{Xyl}}$} & $266(11747)$ & 298 & 4.16 & 1.39 & 0.06 & 386 & $1.56^{e}$ \\
\hline & $272(10300)$ & & & & & & $1.71(88 \%)$ \\
\hline & $280(5813)$ & & & & & & $0.14(12 \%)$ \\
\hline \multirow[t]{3}{*}{$4^{\mathrm{Xyl}}$} & $266(15669)$ & 299 & 4.15 & 1.36 & 0.07 & 393 & $1.46(48 \%)$ \\
\hline & $272(13949)$ & & & & & & $0.26(52 \%)$ \\
\hline & $280(9100)$ & & & & & & \\
\hline
\end{tabular}

${ }^{a}$ Recorded in an aerated $\mathrm{CH}_{2} \mathrm{Cl}_{2}$ solution at $\mathrm{rt}^{b}{ }^{b}$ Calculated from the lowest energy crossing point between the normalized absorption and emission $\operatorname{spectra}\left(E_{\text {opt }}[\mathrm{eV}]=1240.5 / \lambda_{\text {cross }}[\mathrm{nm}]\right) \cdot{ }^{c} 9,10$-Diphenylanthracene was used as standard $\left(0.97\right.$ in cyclohexane). ${ }^{41}{ }^{d}$ Recorded at $77 \mathrm{~K}$ in a $1: 1$ $\mathrm{CH}_{2} \mathrm{Cl}_{2} / \mathrm{CHCl}_{3}$ glassy matrix. ${ }^{e}$ Monoexponential fitting.

Luminescence studies of air-equilibrated $\mathrm{CH}_{2} \mathrm{Cl}_{2}$ solutions of all borazine derivatives showed significant radiative UV emission profiles $\left(\lambda_{\max }=266,272\right.$, and $280 \mathrm{~nm}$, Table 1$)$ and very short lifetimes $\left(\tau_{\mathrm{fl}}=1.24-1.66 \mathrm{~ns}\right.$, Table 1$)$ consistent with the presence of excited singlet radiative deactivation. No significant changes in the emission profiles were observed at $77 \mathrm{~K}$ for the fluorescence spectra. All solutions showed very low quantum yields $\left(\Phi_{\mathrm{em}}=2-7 \%\right.$; Table 1). These data are in line with those obtained with highly doped borazino-polyphenylenes, for which high BN dosages enhance the deactivation rate of the singlet excited state. ${ }^{29}$ When cooled to $77 \mathrm{~K}$, non-negligible phosphorescence emission has been also observed (Figure 8), showing doublepeak emission profiles, also in line with borazino-polyphenylenes. $^{29}$ Representative phosphorescence lifetime measurements showed long-lasting emission profiles $\left(\tau_{\mathrm{ph}}\right.$ ca. $\sim 1.11-$ $1.56 \mathrm{~s})$.

\section{CONCLUSIONS}

In conclusion, in this paper we have reported the synthesis, through a condensation reaction, of borazino-doped polyphenylene derivatives displaying high doping dosages (16$18 \%)$. The use of MesLi yielded strained derivatives, the latter revealing to be unstable in the presence of moisture. However, in the presence of $\mathrm{XylLi}$, chemically stable derivatives were obtained, with a maximum degree of oligomerization of 16-18 units. Whereas the dimer, trimer, and tetramer could be isolated as pure products, higher oligomers could be only isolated as mixtures and characterized by GPC. The structures of the dimer and trimer molecules were confirmed by X-ray analysis, which nicely showed the presence of the two and three borazine rings spaced by one and two 1,4-aryl bridges, respectively. Notably, the trimer formed a porous crystalline clathrate with pentane at the solid state. Photophysical characterization suggested that the molecules are UV absorbers, with the excitation coefficient linearly scaling with the degree of oligomerization.

\section{EXPERIMENTAL SECTION}

Materials and Methods. Chemicals were purchased from Sigma-Aldrich, Acros Organics, TCI, Apollo Scientific, Alfa Aesar, and Fluorochem and were used as received. Solvents were purchased from Fisher Scientific, whereas deuterated solvents from Eurisotop and Sigma-Aldrich. Tetrahydrofuran (THF) and toluene were dried on a Braun MB SPS- 800 solvent purification system and further dried over activated $4 \AA$ molecular sieves. 2-Bromomesitylene and 2-bromo-1,3-dimethylbenzene were dried over activated $4 \AA$ molecular sieves. Aniline was distilled from $\mathrm{CaH}_{2}$ under $\mathrm{N}_{2}$ and stored away from light in an $\mathrm{N}_{2}$ atmosphere. Aniline was left on $\mathrm{CaH}_{2}$ overnight prior to distillation. Low-temperature baths were prepared using different solvent mixtures depending on the desired temperature: $-84{ }^{\circ} \mathrm{C}$ with ethyl acetate/liq. $\mathrm{N}_{2}$, and 0 ${ }^{\circ} \mathrm{C}$ with ice $/ \mathrm{H}_{2} \mathrm{O}$. Anhydrous conditions were achieved by drying Schlenk tubes or two-neck flasks by flaming with a heat gun under vacuum and purging with nitrogen. The inert atmosphere was maintained using nitrogen-filled balloons equipped with a syringe and needle that was used to penetrate the silicon stoppers used to close the flasks' necks. Additions of liquid reagents were performed using plastic syringes. Degassing of solutions was performed using the freezepump-thaw (fpt) procedure: solutions were frozen using liquid nitrogen and kept under vacuum for $10^{\prime}$ before thawing. Molecular sieves $(4 \AA)$ were activated by heating at $165^{\circ} \mathrm{C}$ under vacuum overnight and by further heating with heat gun under vacuum immediately before use. All reactions were performed in dry conditions and under inert atmosphere unless otherwise stated.

Synthesis of Borazines $1^{\text {Mes }}$ and $2^{\text {Mes }}$. In a flame-dried $20 \mathrm{~mL}$ Schlenk-type flask, aniline $(0.26 \mathrm{~mL}, 2.85 \mathrm{mmol}), p$ phenylendiamine $(0.15 \mathrm{~g}, 1.40 \mathrm{mmol})$, and dry toluene $(6 \mathrm{~mL})$ were added. The mixture was heated at $80{ }^{\circ} \mathrm{C}$ under $\mathrm{Ar}$ and $\mathrm{BCl}_{3}(1 \mathrm{M}$ in heptane, $6.00 \mathrm{~mL}$ ) added dropwise. The resulting suspension was stirred under refluxing conditions for $18 \mathrm{~h}$, then cooled down to rt and subjected to $5 \mathrm{fpt}$ cycles to remove the excess $\mathrm{HCl}$. In parallel, to a solution of 2-bromomesitylene $(0.71 \mathrm{~mL}, 4.70 \mathrm{mmol})$ in dry THF $(15 \mathrm{~mL}),{ }^{t} \mathrm{BuLi}(1.7 \mathrm{M}$ in hexanes, $5.80 \mathrm{~mL}$ ) was added dropwise at $-84{ }^{\circ} \mathrm{C}$. The solution was allowed to warm at $0{ }^{\circ} \mathrm{C}$ and stirred for $10 \mathrm{~min}$. The degassed toluene suspension was thus transferred to the organometallic-containing THF solution at $0{ }^{\circ} \mathrm{C}$ and allowed to react for $18 \mathrm{~h}$ at $\mathrm{rt}$. The final mixture was diluted with EtOAc $(90 \mathrm{~mL})$ and washed with water $(3 \times 100 \mathrm{~mL})$ and brine $(50 \mathrm{~mL})$. The organic layer was dried over $\mathrm{MgSO}_{4}$ and evaporated under reduced pressure. The products were purified by silica gel column chromatography (eluent: PE*/ 
$\left.\mathrm{CH}_{2} \mathrm{Cl}_{2} 8: 2\right)$ to afford $\mathbf{1}^{\text {Mes }}(36 \mathrm{mg}, 6 \%$ ) as a white powder. Additionally, a mixture of other products was obtained. These were separated by Rec-GPC using $\mathrm{CHCl}_{3}$ as eluent to afford $2^{\text {Mes }}(40 \mathrm{mg}, 5 \%)$ as a white powder. *Petroleum ether.

$1^{\text {Mes }}$ (Data According to Literature). ${ }^{1} \mathrm{H}$ NMR (400 MHz, $\left.\mathrm{CDCl}_{3}\right): \delta 6.84-6.70(\mathrm{~m}, 15 \mathrm{H}), 6.33(\mathrm{~s}, 6 \mathrm{H}), 2.23(\mathrm{~s}, 18 \mathrm{H})$, $1.97(\mathrm{~s}, 9 \mathrm{H}) .{ }^{13} \mathrm{C} \mathrm{NMR}\left(126 \mathrm{MHz}, \mathrm{CD}_{2} \mathrm{Cl}_{2}\right): \delta 146.42,137.35$, $136.17,127.12,126.81,126.28,124.27,23.12,21.15 .{ }^{11} \mathrm{~B}$ NMR $\left(128 \mathrm{MHz}, \mathrm{CDCl}_{3}\right): \delta 37.02$.

$2^{\text {Mes }} \cdot \mathrm{mp}:>300{ }^{\circ} \mathrm{C} .{ }^{1} \mathrm{H}$ NMR $\left(400 \mathrm{MHz}, \mathrm{CDCl}_{3}\right): \delta 6.69(\mathrm{~s}$, $20 \mathrm{H}), 6.39$ (s, 8H), $6.29(\mathrm{~s}, 4 \mathrm{H}), 6.12(\mathrm{~s}, 4 \mathrm{H}), 2.15(\mathrm{~s}, 12 \mathrm{H})$, $2.10(\mathrm{~s}, 12 \mathrm{H}), 1.95(\mathrm{~s}, 6 \mathrm{H}), 1.89(\mathrm{~s}, 24 \mathrm{H}) .{ }^{13} \mathrm{C}$ NMR $(100$ $\left.\mathrm{MHz}, \mathrm{CDCl}_{3}\right): \delta 146.25,141.97,137.45,137.33,136.61$, $136.10,135.52,127.24,126.55,126.39,126.20,125.83,124.05$, 22.87, 22.58, 21.30, 21.15. MALDI-TOF-HRMS: $[\mathrm{M}]^{+}$calcd for $\left[\mathrm{C}_{84} \mathrm{H}_{90} \mathrm{~B}_{6} \mathrm{~N}_{6}\right]^{+}, 1248.7785$; found, 1248.7786. IR not recorded because of instability of the molecule. Crystals suitable for X-ray diffraction were obtained from slow evaporation of $\mathrm{CHCl}_{3}$.

Synthesis of Borazines $1^{X y l}, 2^{X y l}, 3^{X y l}$, and $4^{X y l}$. In a flame-dried $100 \mathrm{~mL}$ Schlenk-type flask, aniline $(0.49 \mathrm{~mL}, 5.37$ mmol), p-phenylendiamine $(0.29 \mathrm{~g}, 2.68 \mathrm{mmol})$, and dry toluene $(12 \mathrm{~mL})$ were added. The mixture was heated at $80{ }^{\circ} \mathrm{C}$ under $\mathrm{N}_{2}$ and $\mathrm{BCl}_{3}(1 \mathrm{M}$ in heptane, $11.5 \mathrm{~mL})$ added dropwise. The reaction was cooled down to $0{ }^{\circ} \mathrm{C}$ and stirred for $10 \mathrm{~min}$. The resulting suspension was heated under refluxing conditions for $18 \mathrm{~h}$, cooled down to rt, and subjected to $5 \mathrm{fpt}$ cycles to remove the excess $\mathrm{HCl}$. In parallel, to a solution of 2-bromo-1,3-dimethylbenzene $(2.16 \mathrm{~mL}, 16.08$ $\mathrm{mmol})$ in dry THF $(40 \mathrm{~mL}),{ }^{n} \mathrm{BuLi}(1.6 \mathrm{M}$ in hexanes, 10.70 $\mathrm{mL}$ ) was added dropwise at $-84^{\circ} \mathrm{C}$. The solution was allowed to warm at $0{ }^{\circ} \mathrm{C}$, and stirred for $10 \mathrm{~min}$. The degassed toluene suspension was transferred to the organometal-containing THF solution at $0{ }^{\circ} \mathrm{C}$ and allowed to react for $18 \mathrm{~h}$ at rt. The final mixture was diluted with EtOAc $(150 \mathrm{~mL})$ and washed with water $(2 \times 100 \mathrm{~mL})$ and brine $(2 \times 100 \mathrm{~mL})$. The organic layer was dried over $\mathrm{MgSO}_{4}$ and evaporated under reduced pressure. The solid residue was precipitated from cold $\mathrm{MeOH}$ and filtered. The resulting white solid was purified by silica gel column chromatography (eluent: $\mathrm{PE} / \mathrm{CH}_{2} \mathrm{Cl}_{2}$ 7:3) to afford $1^{\mathrm{Xyl}}(182 \mathrm{mg}, 16 \%)$ and $2^{\mathrm{Xyl}}(107 \mathrm{mg}, 7 \%)$ as white powders. Additionally, three fractions composed by mixtures of products were obtained. The first two fractions were purified by Rec-GPC using $\mathrm{CHCl}_{3}$ as eluent. Purification of the first fraction afforded $3^{\text {Xyl }}(19 \mathrm{mg}, 1 \%)$ and $2^{\text {XylOH }}(22 \mathrm{mg}, 2 \%)$ as white powders. Purification of the second fraction gave $4^{\mathrm{Xyl}}$ (iso and $n$ isomers), which was further purified with preparative thin-layer chromatography (eluent: $\mathrm{PE} / \mathrm{CH}_{2} \mathrm{Cl}_{2}$ $6: 4)$ to give the desired product $(2 \mathrm{mg}, 0.1 \%)$. The third fraction was analyzed by GPC at Warwick University and resulted in a mixture of hydroxylated oligomers (see Section S4 of the Supporting Information for GPC analysis).

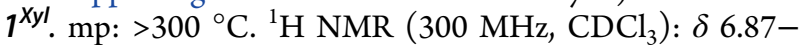
$6.84(\mathrm{~m}, 6 \mathrm{H}), 6.80-6.70(\mathrm{~m}, 12 \mathrm{H}), 6.53(\mathrm{~d}, J=7.5 \mathrm{~Hz}, 6 \mathrm{H})$ $2.30(\mathrm{~s}, 18 \mathrm{H}) .{ }^{13} \mathrm{C}$ NMR $\left(75 \mathrm{MHz} \mathrm{CDCl}_{3}\right): \delta 146.09,137.50$, 127.14, 126.98, 126.91, 125.39, 124.62, 23.29. ${ }^{11} \mathrm{~B}$ NMR (160 $\left.\mathrm{MHz}, \mathrm{CDCl}_{3}\right): \delta 36.43$. IR (ATR) $\nu\left(\mathrm{cm}^{-1}\right): 3061.03,3008.95$, $2947.23,2916.37,2854.65,1595.13,1489.05,1427.32$, 1355.96, 1288.45, 1072.42, 1026.13, 765.74, 748.38, 727.16, 696.30, 567.07, 528.50, 518.85. $\mathrm{AP}^{+}$-HRMS: $[\mathrm{M}+\mathrm{H}]^{+}$calcd for $\left[\mathrm{C}_{42} \mathrm{H}_{43} \mathrm{~B}_{3} \mathrm{~N}_{3}\right]^{+}, 622.3736$; found, 622.3766. Crystals suitable for $\mathrm{X}$-ray diffraction were obtained from slow evaporation of $\mathrm{CHCl}_{3}$.
$2^{X y l} . \mathrm{mp}:>300{ }^{\circ} \mathrm{C} .{ }^{1} \mathrm{H} \mathrm{NMR}\left(500 \mathrm{MHz}, \mathrm{CDCl}_{3}\right): \delta 6.85(\mathrm{t}$, $J=6.5 \mathrm{~Hz}, 4 \mathrm{H}), 6.73(\mathrm{~s}, 22 \mathrm{H}), 6.59-6.51(\mathrm{~m}, 12 \mathrm{H}), 6.24(\mathrm{~s}$, $4 \mathrm{H}), 2.20$ (s, 12H), 1.99 (s, 24H). ${ }^{13} \mathrm{C}$ NMR (126 MHz, $\left.\mathrm{CDCl}_{3}\right): \delta 145.94,142.09,137.57,137.50,127.09,126.79$, 126.65, 125.86, 125.63, 125.34, 124.40, 23.06, 22.94. ${ }^{11} \mathrm{~B}$ NMR $\left(160 \mathrm{MHz}, \mathrm{CDCl}_{3}\right): \delta$ 37.13. IR (ATR) $\nu\left(\mathrm{cm}^{-1}\right): 3057.17$, 2943.37, 2914.44, 2858.51, 1595.13, 1489.05, 1452.4, 1352.10, 1288.45, 1070.49, 1018.41, 765.74, 698.23. MALDI-HRMS: $[\mathrm{M}]^{+}$calcd for $\left[\mathrm{C}_{78} \mathrm{H}_{78} \mathrm{~B}_{6} \mathrm{~N}_{6}\right]^{+}, 1164.6846$; found, 1164.6812 . Crystals suitable for $\mathrm{X}$-ray diffraction were obtained from slow diffusion of pentane in $\mathrm{CHCl}_{3}$.

$2^{\text {XylOH }} . \mathrm{mp}:>300{ }^{\circ} \mathrm{C} .{ }^{1} \mathrm{H} \mathrm{NMR}\left(500 \mathrm{MHz}, \mathrm{CDCl}_{3}\right): \delta 7.07$ $(\mathrm{t}, J=7.7 \mathrm{~Hz}, 1 \mathrm{H}), 7.00-6.96(\mathrm{~m}, 2 \mathrm{H}), 6.79-6.78(\mathrm{~m}, 4 \mathrm{H})$, 6.76-6.64 (m, 16H), 6.60-6.56 (m, 2H), 6.53-6.48 (m, $10 \mathrm{H}) 6.43(\mathrm{t}, J=8.1 \mathrm{~Hz}, 3 \mathrm{H}), 6.33(\mathrm{~d}, J=8.5 \mathrm{~Hz}, 1 \mathrm{H}), 3.49-$ $3.17(\mathrm{~d}, 1 \mathrm{H}, \mathrm{OH}$ proton visible as double singlet because of exchange), 2.23 (s, 6H), 2.19 (s, 9H), 2.06 (br s, 6H), 1.98 (s, $6 \mathrm{H}), 1.90(\mathrm{~s}, 3 \mathrm{H}) .{ }^{13} \mathrm{C} \mathrm{NMR}\left(126 \mathrm{MHz}, \mathrm{CDCl}_{3}\right): \delta 146.13$, $146.04,145.95,144.32,143.54,142.87,140.14,139.55,137.56$, 137.52, 137.41, 137.25, 127.96, 127.48, 127.45, 127.19, 127.07, $126.97,126.91,126.87,126.85,126.80,126.67,125.89,125.86$, $125.56,125.41,125.38,125.30,125.10,124.61,124.56,124.38$, 23.17, 23.12, 22.92, 22.83. ${ }^{11} \mathrm{~B}$ NMR (160 MHz, $\left.\mathrm{CDCl}_{3}\right): \delta$ $36.59,26.27$. IR (ATR) $\nu\left(\mathrm{cm}^{-1}\right): 3601.10,3059.10,2916.37$, $2854.65,1678.07,1597.06,1508.33,1490.97,1452.40$, $1425.40,1354.03,1307.74,1213.23,1163.08,1122.57$, 1074.35, 846.75, 765.74, 748.38, 729.09, 719.45, 696.30, 657.73, 607.58, 574.79, 526.57. ASAP $^{+}$-HRMS: $[\mathrm{M}]^{+}$calcd for $\left[\mathrm{C}_{70} \mathrm{H}_{70} \mathrm{~B}_{6} \mathrm{~N}_{6} \mathrm{O}\right]^{+}, 1076.6169$; found, 1076.6207. Crystals suitable for $\mathrm{X}$-ray diffraction were obtained from slow evaporation of petroleum ether $\mathrm{CH}_{2} \mathrm{Cl}_{2}$ mixture.

$3^{X y l} . \mathrm{mp}:>300{ }^{\circ} \mathrm{C} .{ }^{1} \mathrm{H} \mathrm{NMR}\left(500 \mathrm{MHz}, \mathrm{CDCl}_{3}\right): \delta 6.91(\mathrm{t}$, $J=7.5 \mathrm{~Hz}, 1 \mathrm{H}), 6.83-6.75(\mathrm{~m}, 7 \mathrm{H}), 6.70-6.68(\mathrm{~m}, 21 \mathrm{H})$, 6.61-6.60 (m, 3H), 6.57-6.52 (m, 12H), 6.50-6.47 (m, 8H), $6.13(\mathrm{~d}, J=8.7 \mathrm{~Hz}, 4 \mathrm{H}), 6.04(\mathrm{~d}, J=8.7 \mathrm{~Hz}, 4 \mathrm{H}), 2.16(\mathrm{~s}$, $12 \mathrm{H}), 1.95(\mathrm{~s}, 12 \mathrm{H}), 1.94(\mathrm{~s}, 12 \mathrm{H}), 1.80(\mathrm{~s}, 12 \mathrm{H}), 1.62(\mathrm{~s}$, $6 \mathrm{H}) .{ }^{13} \mathrm{C} \mathrm{NMR}\left(126 \mathrm{MHz}, \mathrm{CDCl}_{3}\right): \delta 145.97,145.94,141.97$, 141.92 , 137.58, 137.55, 137.48, 127.13, 127.07, 126.76, 126.68, $126.63,126.51,126.39,126.00,125.64,125.60,125.51,125.32$, 124.39, 124.20, 23.07, 22.97, 22.95, 22.75, 22.52. ${ }^{11} \mathrm{~B}$ NMR $\left(160 \mathrm{MHz}, \mathrm{CDCl}_{3}\right): \delta 39.21$. IR (ATR) $\nu\left(\mathrm{cm}^{-1}\right): 3039.81$, 2916.37, 2854.65, 1597.06, 1425.40, 1352.10, 1301.95, 1288.45, 763.81, 698.23. MALDI-TOF-HRMS: $[\mathrm{M}]^{+}$calcd for $\left[\mathrm{C}_{114} \mathrm{H}_{114} \mathrm{~B}_{9} \mathrm{~N}_{9}\right]^{+}, 1708.0035$; found, 1707.9987. Crystals suitable for $\mathrm{X}$-ray diffraction were obtained from slow diffusion of pentane in $\mathrm{CHCl}_{3}$.

$4^{X y l}$. mp: $>300{ }^{\circ} \mathrm{C} .{ }^{1} \mathrm{H}$ NMR $\left(500 \mathrm{MHz}, \mathrm{CD}_{2} \mathrm{Cl}_{2}\right): \delta 6.93-$ $6.44(\mathrm{~m}, 69 \mathrm{H}), 6.21(\mathrm{~d}, J=8.7 \mathrm{~Hz}, 1 \mathrm{H}), 6.15-6.13(\mathrm{~m}, 3 \mathrm{H})$, 6.06-6.03 (m, 3H), $5.99(\mathrm{~d}, J=0.7 \mathrm{~Hz}, 2 \mathrm{H}), 2.26-2.12(\mathrm{~m}$, $18 \mathrm{H}), 1.97-1.95(\mathrm{~m}, 18 \mathrm{H}), 1.81(\mathrm{~s}, 9 \mathrm{H}), 1.80(\mathrm{~s}, 3 \mathrm{H}), 1.62(\mathrm{~s}$, $6 \mathrm{H}), 1.52(\mathrm{~s}, 18 \mathrm{H})$. IR (ATR) $\nu\left(\mathrm{cm}^{-1}\right): 3055.24,2920.23$, 2854.65, 1597.06, 1492.9, 1454.33, 1427.32, 1357.89, 1303.88. MALDI-TOF-HRMS: $[\mathrm{M}]^{+}$calcd for $\left[\mathrm{C}_{150} \mathrm{H}_{150} \mathrm{~B}_{12} \mathrm{~N}_{12}\right]^{+}$, 2251.3223; found, 2251.3375. ${ }^{13} \mathrm{C}$ not recorded because of the low amount of product obtained.

Oligomeric Fraction. IR (ATR) $\nu\left(\mathrm{cm}^{-1}\right)$ : 3612.67, 3057.17, 2945.30, 2916.37, 1597.06, 1490.97, 1355.96, 1307.74, 765.74, 698.23. ${ }^{11} \mathrm{~B}$ NMR $\left(160 \mathrm{MHz}, \mathrm{CDCl}_{3}\right): \delta$ 37.53, 25.17. For GPC analysis see Section S4. 


\section{ASSOCIATED CONTENT}

\section{S Supporting Information}

The Supporting Information is available free of charge on the ACS Publications website at DOI: 10.1021/acsomega.9b00830.

Synthetic protocols and spectroscopic characterizations (PDF)

Crystallographic data (CIF)

Crystallographic data (CIF)

Crystallographic data (CIF)

Crystallographic data (CIF)

Crystallographic data (CIF)

Crystallographic data (CIF)

\section{AUTHOR INFORMATION}

\section{Corresponding Author}

*E-mail: bonifazid@cardiff.ac.uk.

\section{ORCID $\odot$}

Nicola Demitri: 0000-0003-0288-3233

Davide Bonifazi: 0000-0001-5717-0121

\section{Author Contributions}

§.D. and D.M. equally contributed to this work.

\section{Notes}

The authors declare no competing financial interest.

\section{ACKNOWLEDGMENTS}

D.B. and J.D. gratefully acknowledge the EU through the MCRISE project "INFUSION" and Cardiff University for the financial support. The authors thank T. Battisti of the School of Chemistry at Cardiff University for the help with the photophysical characterization.

\section{REFERENCES}

(1) Stępień, M.; Gońka, E.; Żyła, M.; Sprutta, N. Heterocyclic Nanographenes and Other Polycyclic Heteroaromatic Compounds: Synthetic Routes, Properties, and Applications. Chem. Rev. 2017, 117, 3479-3716.

(2) Hirai, M.; Tanaka, N.; Sakai, M.; Yamaguchi, S. Structurally Constrained Boron, Nitrogen, Silicon, and Phosphorus-Centered Polycyclic $\pi$-Conjugated Systems. Chem. Rev. 2019, DOI: 10.1021/ acs.chemrev.8b00637.

(3) Narita, A.; Wang, X.-Y.; Feng, X.; Müllen, K. New advances in nanographene chemistry. Chem. Soc. Rev. 2015, 44, 6616-6643.

(4) Wang, J.-Y.; Pei, J. BN-embedded aromatics for optoelectronic applications. Chin. Chem. Lett. 2016, 27, 1139-1146.

(5) Huang, J.; Li, Y. BN Embedded Polycyclic $\pi$-Conjugated Systems: Synthesis, Optoelectronic Properties, and Photovoltaic Applications. Front. Chem. 2018, 6, 341.

(6) Bosdet, M. J. D.; Piers, W. E. B-N as a C-C substitute in aromatic systems. Can. J. Chem. 2009, 87, 8-29.

(7) Campbell, P. G.; Marwitz, A. J. V.; Liu, S.-Y. Recent Advances in Azaborine Chemistry. Angew. Chem., Int. Ed. 2012, 51, 6074-6092.

(8) Helten, H. B=N Units as Part of Extended $\pi$-Conjugated Oligomers and Polymers. Chem.-Eur. J. 2016, 22, 12972-12982.

(9) Wang, X.-Y.; Wang, J. Y.; Pei, J. BN heterosuperbenzenes: Synthesis and properties. Chem.-Eur. J. 2015, 21, 3528-3539.

(10) Liu, Z.; Marder, T. B. B-N versus C-C: How similar are they? Angew. Chem., Int. Ed. 2008, 47, 242-244.

(11) Lorenzo-García, M. M.; Bonifazi, D. Renaissance of an Old Topic: From Borazines to BN-doped Nanographenes. Chim. Int. J. Chem. 2017, 71, 550-557.

(12) Karamanis, P.; Otero, N.; Pouchan, C. Unleashing the quadratic nonlinear optical responses of graphene by confining white-graphene (h -BN) sections in its framework. J. Am. Chem. Soc. 2014, 136, 7464-7473.

(13) Otero, N.; Karamanis, P.; El-Kelany, K. E.; Rérat, M.; Maschio, L.; Civalleri, B.; Kirtman, B. Exploring the linear optical properties of borazine $\left(\mathrm{B}_{3} \mathrm{~N}_{3}\right)$ doped graphenes. OD flakes vs $2 \mathrm{D}$ sheets. J. Phys. Chem. C 2017, 121, 709-722.

(14) Otero, N.; Pouchan, C.; Karamanis, P. Quadratic nonlinear optical (NLO) properties of borazino $\left(\mathrm{B}_{3} \mathrm{~N}_{3}\right)$-doped nanographenes. J. Mater. Chem. C 2017, 5, 8273-8287.

(15) Bosdet, M. J. D.; Piers, W. E.; Sorensen, T. S.; Parvez, M. 10aAza-10b-borapyrenes: Heterocyclic analogues of pyrene with internalized BN moieties. Angew. Chem., Int. Ed. 2007, 46, 49404943.

(16) Jaska, C. A.; Bosdet, M. J. D.; Parvez, M.; Sorensen, T. S.; Emslie, D. J. H.; Piers, W. E. Triphenylene Analogues with $\mathrm{B}_{2} \mathrm{~N}_{2} \mathrm{C}_{2}$ Cores: Synthesis, Structure, Redox Behavior, and Photophysical Properties. J. Am. Chem. Soc. 2006, 128, 10885-10896.

(17) Wang, X.-Y.; Zhuang, F.-D.; Wang, R.-B.; Wang, X.-C.; Cao, X.Y.; Wang, J.-Y.; Pei, J. A straightforward strategy toward large BNembedded $\pi$-systems: Synthesis, structure, and optoelectronic properties of extended BN heterosuperbenzenes. J. Am. Chem. Soc. 2014, 136, 3764-3767.

(18) Yang, D.-T.; Nakamura, T.; He, Z.; Wang, X.; Wakamiya, A.; Peng, T.; Wang, S. Doping Polycyclic Arenes with Nitrogen-BoronNitrogen (NBN) Units. Org. Lett. 2018, 20, 6741-6745.

(19) Hatakeyama, T.; Shiren, K.; Nakajima, K.; Nomura, S.; Nakatsuka, S.; Kinoshita, K.; Ni, J.; Ono, Y.; Ikuta, T. Ultrapure Blue Thermally Activated Delayed Fluorescence Molecules: Efficient HOMO-LUMO Separation by the Multiple Resonance Effect. Adv. Mater. 2016, 28, 2777-2781.

(20) Wang, X.-Y.; Zhuang, F.-D.; Wang, J.-Y.; Pei, J. Incorporation of polycyclic azaborine compounds into polythiophene-type conjugated polymers for organic field-effect transistors. Chem. Commun. 2015, 51, 17532-17535.

(21) Nakatsuka, S.; Yasuda, N.; Hatakeyama, T. Four-Step Synthesis of $\mathrm{B}_{2} \mathrm{~N}_{2}$-Embedded Corannulene. J. Am. Chem. Soc. 2018, 140, $13562-13565$.

(22) Hatakeyama, T.; Hashimoto, S.; Oba, T.; Nakamura, M. Azaboradibenzo[6]helicene: Carrier inversion induced by helical homochirality. J. Am. Chem. Soc. 2012, 134, 19600-19603.

(23) Bonifazi, D.; Fasano, F.; Lorenzo-garcia, M. M.; Marinelli, D.; Oubaha, H.; Tasseroul, J. Boron-nitrogen doped carbon scaffolding: organic chemistry, self-assembly and materials applications of borazine and its derivatives. Chem. Commun. 2015, 51, 15222-15236.

(24) Lorenz, T.; Crumbach, M.; Eckert, T.; Lik, A.; Helten, H. Poly ( $\mathrm{p}$-phenylene iminoborane): A Boron-Nitrogen Analogue of Poly ( $\mathrm{p}$ -phenylene vinylene). Angew. Chem., Int. Ed. 2017, 56, 2780-2784.

(25) Resendiz-Lara, D. A.; Stubbs, N. E.; Arz, M. I.; Pridmore, N. E.; Sparkes, H. A.; Manners, I. Boron-nitrogen main chain analogues of polystyrene: Poly(B -aryl) aminoboranes via catalytic dehydrocoupling. Chem. Commun. 2017, 53, 11701-11704.

(26) Staubitz, A.; Sloan, M. E.; Robertson, A. P.; Friedrich, A.; Schneider, S.; Gates, P. J.; Schmedt auf der Günne, J.; Manners, I. Catalytic Dehydrocoupling/Dehydrogenation of $\mathrm{N}$-MethylamineBorane and Ammonia-Borane: Synthesis and Characterization of High Molecular Weight Polyaminoboranes. J. Am. Chem. Soc. 2010, 132, 13332-13345.

(27) Staubitz, A.; Presa Soto, A.; Manners, I. Iridium-catalyzed dehydrocoupling of primary amine-borane adducts: A route to high molecular weight polyaminoboranes, boron-nitrogen analogues of polyolefins. Angew. Chem., Int. Ed. 2008, 47, 6212-6215.

(28) Riensch, N. A.; Deniz, A.; Kühl, S.; Müller, L.; Adams, A.; Pich, A.; Helten, $\mathrm{H}$. Borazine-based inorganic-organic hybrid cyclomatrix microspheres by silicon/boron exchange precipitation polycondensation. Polym. Chem. 2017, 8, 5264-5268.

(29) Marinelli, D.; Fasano, F.; Najjari, B.; Demitri, N.; Bonifazi, D. Borazino-Doped Polyphenylenes. J. Am. Chem. Soc. 2017, 139, 55035519. 
(30) Jackson, K. T.; Reich, T. E.; El-Kaderi, H. M. Targeted synthesis of a porous borazine-linked covalent organic framework. Chem. Commun. 2012, 48, 8823-8825.

(31) Kervyn, S.; Fenwick, O.; Di Stasio, F.; Shin, Y. S.; Wouters, J.; Accorsi, G.; Osella, S.; Beljonne, D.; Cacialli, F.; Bonifazi, D. Polymorphism, fluorescence, and optoelectronic properties of a borazine derivative. Chem.-Eur. J. 2013, 19, 7771-7779.

(32) Kalashnyk, N.; Nagaswaran, P. G.; Kervyn, S.; Riello, M.; Moreton, B.; Jones, T. S.; De Vita, A.; Bonifazi, D.; Costantini, G. Self-assembly of decoupled borazines on metal surfaces: the role of the peripheral groups. Chem.-Eur. J. 2014, 20, 11856-11862.

(33) Kervyn, S.; Kalashnyk, N.; Riello, M.; Moreton, B.; Tasseroul, J.; Wouters, J.; Jones, T. S.; De Vita, A.; Costantini, G.; Bonifazi, D. "Magic" surface clustering of borazines driven by repulsive intermolecular forces. Angew. Chem., Int. Ed. 2013, 52, 7410-7414.

(34) Schwarz, M.; Garnica, M.; Fasano, F.; Demitri, N.; Bonifazi, D.; Auwärter, W. BN-Patterning of Metallic Substrates through Metal Coordination of Decoupled Borazines. Chem.-Eur. J. 2018, 24, 9565-9571.

(35) Sánchez-Sánchez, C.; Brüller, S.; Sachdev, H.; Müllen, K.; Krieg, M.; Bettinger, H. F.; Nicolaï, A.; Meunier, V.; Talirz, L.; Fasel, R.; et al. On-Surface Synthesis of BN-Substituted Heteroaromatic Networks. ACS Nano 2015, 9, 9228-9235.

(36) Dosso, J.; Tasseroul, J.; Fasano, F.; Marinelli, D.; Biot, N.; Fermi, A.; Bonifazi, D. Synthesis and Optoelectronic Properties of Hexa-peri-hexabenzoborazinocoronene. Angew. Chem., Int. Ed. 2017, $56,4483-4487$.

(37) Nagasawa, K. Borazines Stable to Hydrolysis. Inorg. Chem. 1966, 5, 442-445.

(38) Reich, T. E.; Behera, S.; Jackson, K. T.; El-Kaderi, H. M.; Jena, P. Highly selective $\mathrm{CO}_{2} / \mathrm{CH}_{4}$ gas uptake by a halogen-decorated borazine-linked polymer. J. Mater. Chem. 2012, 22, 13524-13528.

(39) Reich, T. E.; Jackson, K. T.; Li, S.; Jena, P.; El-Kaderi, H. M. Synthesis and characterization of highly porous borazine-linked polymers and their performance in hydrogen storage application. $J$. Mater. Chem. 2011, 21, 10629-10632.

(40) Wakamiya, A.; Ide, T.; Yamaguchi, S. Toward $\pi$-conjugated molecule bundles: Synthesis of a series of $\mathrm{B}, \mathrm{B}^{\prime}, \mathrm{B}^{\prime \prime}$-trianthryl-N, $\mathrm{N}^{\prime}, \mathrm{N}^{\prime \prime}$ triarylborazines and the bundle effects on their properties. J. Am. Chem. Soc. 2005, 127, 14859-14866.

(41) Suzuki, K.; Kobayashi, A.; Kaneko, S.; Takehira, K.; Yoshihara, T.; Ishida, H.; Shiina, Y.; Oishi, S.; Tobita, S. Reevaluation of absolute luminescence quantum yields of standard solutions using a spectrometer with an integrating sphere and a back-thinned CCD detector. Phys. Chem. Chem. Phys. 2009, 11, 9850-9860. 